\title{
Reviewing Translated Texts:Challenges and Opportunities
}

\section{Sachidananda Mohanty}

\begin{abstract}
Most deliberations in the field of translation tend to regrettably leave out the crucial task of reviewing. In a multilingual country like ours, reviews of translation serve as the prism through which (literary) texts get disseminated across linguistic and cultural barriers. While translation enthusiasts give reviewing a mandatory nod, most critics seem to think that it is an institutional matter that involves the predilections of editors and so called reviewers, over which others have little or no control. Consequently, reviewing of translated texts gets done in a haphazard and shoddy manner. Usually, the stress is on the biography of the authors, his/her cultural context and milieu, and predictably, the gist of the text(s) translated. At the end, the reviewer may in passing throw in a paragraph or two about the -quality of translation without going into the specifics. This paper will underline the crucial importance of reviewing, a totally neglected field, and offer a thumb rule account of what an ideal reviewer could do or hope to achieve. Examples will be cited from published pieces to substantiate aspects of bad reviewing while signaling features that could act as constituents of a good review.
\end{abstract}

We may begin this exercise by stating the obvious: that reviewing of translated texts is a form of reviewing, a genre that has managed to hold its own in the domain of public culture. Beginning with the era of print capitalism and the emergence of a leisured reading class, the act of reviewing took centre stage. At its best, the form has attracted some of the best literary minds. It has served as a forum for discursive analysis and creativity. With lesser practitioners, however, the medium has lasted as a second rate activity that fills up journalistic space.

Translation Today Vol. 5 No. 1 \& 22008 ㄷ CIIL 2008 
While reviewing is rightly recognized as widespread and influential, the principles of all good reviewing are seldom articulated or publicly debated. They are assumed to exist in the ideal prototype. Like all good teaching, good reviewing, it is believed, is recognised when seen and encountered.

In a significant sense, the problems of reviewing translated texts are practically the same as the problem of reviewing in general. The pressure of time, the constraint in publication space, the proneness to hype and sensationalism, so characteristic of our times, the perceived shallowness of popular taste-all these remain the bane of both the activities.

And thus, there seems to be a mismatch between the so called ideal vis-à-vis the real types in the art of reviewing. Consequently, a good literary review, it seems to me, may ask the following: Is this work basically a derivative piece or does it break new ground? Does it enhance our understanding or does it merely confirm what we already know? Does it provoke us to new thinking by raising fundamental questions or does it merely chronicle facts? Does it use new information and offer new insights or does it rehash old arguments? The possibilities are virtually endless.

Reviewing translations clearly entails greater challenges. All translations are a form of negotiation, between cultures, ideologies, texts and politics. Translations, as George Steiner instructively told us, are not a matter of fidelity or betrayal of the so called original text. They draw attention to the process rather than the product. They draw out insightfully the deeper layers embedded in the literary artefact. Many questions thus become important. Who is the translator? Where is he/she located? How does he/she deal with the translated text? How does he/she handle the textual traditions and the contextual factors? What knowledge of intellectual or publication history does he/she bring to bear on the reviewing of translations? For the more sophisticated and astute reviewer dealing with an exceptional piece of translation, there may be further questions: How does it become a 
shaping force for literary change and development? How does it create new genres and shape the literary sensibility? ${ }^{1}$ One may think of the sonnet form that originates in Italian and in the space of two centuries spreads across the European literatures, changing its nature very slightly as it goes so that by the time we have the Shakespearean sonnet it is very different from the Petrarchan. And then there is the instance of the translations of T.S. Eliot into modern Indian languages ${ }^{2}$. The corollary too may be raised: Why do some texts not become a shaping force for literary change?

Another challenge for the translator and the reviewer is to determine the ethics for good translations. In a conversation with me that appeared in The Hindu's Literary Review dated Sunday, 20 December, 1998, this is what Susan Bassnett said:

The question of ethics is a very interesting one. It has not been fashionable in North America or Europe to talk about morality and literature. And I think the tide is turning now. I think now the moral and ethical questions are coming back on the agenda. If you look at the actual terms of reference of the International Federation of Translators, with reference to instructions to translators, there are ethical questions raised there. One of them is that if the translator does not agree with the ideology or contents of a text, he or she should not translate it, that the translator himself should not go against his moral principles. I think the question of the morality of the translator is probably something that is going to occupy us over the next few years. I can see this becoming a very big issue. And linked to that of course is the question of quality. This again is a problem because Western literary tradition has for 20 or 30 years not wanted to make value judgments. Of course, we all say, this is a good translation, that is a bad translation. So we must have some criteria. And I think it is important to remember the historical dimension. What was deemed to be a wonderful translation in 1860 might be hopeless in 1920, fashionable in 1950 and dead in 1990. So we need to take this aspect into account"3 
Clearly the question of the ethics of the translator is as important as the ethics of the reviewer. In the McWorld global culture that affirms the primacy of the English language and monoculture, how does the responsible and discerning reviewer deal with the question of multiple languages and traditions that all translations presuppose? In the post-colonial context, as U. R. Ananthamurthy once said, the more educated we are, the less number of languages we speak. And so also about readership.

The editors of journals, to be fair to them, are in a way, trying to cater to what they think their audience is capable of and willing to access. It is true that they have a role to educate their readers. But then that requires risk and courage. Even the best of journals like The Heritage and the Indian Review of Books folded up due to financial reasons. This remains one more challenge before the reader.

The ground reality is known to most of us. Shoddy translations that show a blithe ignorance of many of the basic principles underlined above, commissioning editors that are more interested in flaunting personal controversies to boost circulation sales, banal plot summaries with inane comments lifted from the blurbs and jacket covers. Malice, personal prejudice and predilections often masquerade as the reviewer's judgment. The modern reader, including that of the translated text, it is somehow assumed, is a dumb and passive creature who is interested basically in the storyline. He/she has no time or interest to fathom the world of cultures, texts and literary traditions, of contextual factors and the fascinating play of ideas that intellectual history brings in.

In all these, the reviewers have been at fault. This remains a great challenge and it can be turned into an opportunity. Good reviewing of translation is part of the larger battle against bad reviewing in general, and in the final analysis, against the dictates of the globalized culture that seeks to level down all differences, specificities and diversities. One cannot hope to win by fighting a lone local battle, one needs to establish coalitions with like-minded critics, writers, 
translators, editors and the reading public. We must subject ourselves to greater amount of professionalism. We must be willing to judge our acts as rigorously and as critically as we treat those of others. We must avoid coterie or group activity that sacrifices individual judgments for mercenary ends.

Lest I sound presumptuous and self-righteous, I must also be willing to assume part of the blame myself. Some feel that one could review a book even if one does not know the source language. I have my doubts regarding this. But then, why did I accept to review a book translation from Konkani? How much did I know of true Konkani or its writing traditions? Such efforts inevitably end up in plot summaries and the mandatory last para of critical advice. On the other hand, I believe I have functioned best when I handled a text and its traditions moderately well. Again, the response is going to vary depending on whether I am writing for the Book Review or Biblio or for a literary journal.

An idea that appeals to me is the need to review one's translated text. Katha regularly asks its translators to narrate their experience. This is a challenge that many translators do not undertake. Here again, I have benefited as a translator when I have subjected my task as a translator to all that I hold as essential to the job of a reviewer. The reader would be unaware of this effort. Nevertheless, a broader knowledge of the contextual and literary traditions would contribute to a more mature handling of the translated text.

Thus, reviewing translated texts entails both challenges and opportunities. There could be individual and institutional responses. At the institutional level, in our Departments of English, Comparative Literature, Translation and Media Studies, we need to frame innovative courses that focus on the art of reviewing. Editors of journals could always pass on their guidelines to the reviewers, just as they have inhouse documentation styles passed on to potential contributors. The problem may appear daunting but one can begin in a modest manner. 
In the final analysis, we must remember that the real challenges in reviewing are not to uphold aesthetic and normative principles important as they are. It is to uphold literary and cultural diversity and the many imaginative ways in which we can respond to cultural globalization. It is the larger battle we must fight even as we choose to train our gaze on the more immediate task at hand: How to review a translated text.

\section{Notes}

1. It has to be noted that "following the appearance of Lawrence's Sons and Lovers, more and more Lawrence works were translated into Chinese and published one after the other. Nevertheless, there were only a few occasional reviews, and those mainly concerned with the artistic aspects of Lawrence's works. The important Lawrence themes-sex and religion were not accidentally neglected, as sex had always been a literary taboo in China", See D. H. Lawrence Studies in China: A Checklist of Works by and about Him.' By Youcheng Jin in D.H.Lawrence Review, 23.1,1991 (pg 47-42). I am grateful to Prof. B. R. Bapuji for this reference.

2. In a separate context it is interesting to note that Christian missionaries had been active as early as the $16^{\text {th }}$ Century in preparing word lists and grammatical descriptions of the languages of the conquered peoples in European colonial empires... a good analysis of a language greatly facilitates the creation of a writing system for it and subsequent translation into it, such analyses have become important preliminary steps to the process of Christianity', See The Politics of Linguistics, by Frederick J. Newmeyer, Chicago: The University of Chicago Press, 1986.

3. 'Translation as a form of Negotiation' Conversation with Susan Bassnett, The Hindu, Sunday, December 20, 1998. Also see, Translation Studies, by Susan Bassnett, London: Methuen, 1980. 